
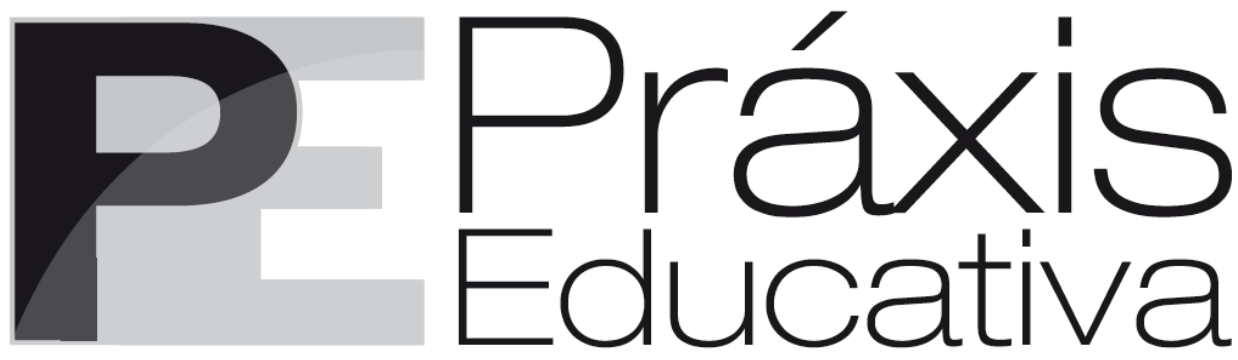

ISSN 1809-4031

elSSN 1809-4309

https://doi.org/10.5212/PraxEduc.v.15.14239.027

\title{
Práticas com modelagem na formação do professor da Educação Básica: a busca por uma nova racionalidade
}

\section{Modeling practices in Basic Education teacher training: the search for a new rationality}

\section{Prácticas de modelación en la formación del profesor de Educación Básica: la búsqueda de una nueva racionalidade}

\author{
Dionísio Burak * \\ iD https:/ / orcid.org/0000-0002-1345-1113 \\ Laynara dos Reis Santos Zontini ${ }^{* *}$ \\ (iD) https://orcid.org/0000-0001-5850-1025
}

\begin{abstract}
Resumo: Este artigo discute a racionalidade técnica na formação docente e a necessidade de uma nova racionalidade que dê conta dos desafios da formação humana na atualidade, sendo abordada a partir dos pressupostos da Modelagem Matemática (MM) na Educação Matemática. Para exemplificar a discussão, inicialmente teórica, apresentamos uma descrição e reflexão de uma prática com MM realizada por professores da Educação Básica em um período de 20 horas. O trabalho desenvolvido com os professores foi parte de uma formação continuada e forneceu os dados da investigação sobre o tema Integração e Construção rural. Foram analisados os resultados da formação orientados pela interrogação: como a prática com Modelagem Matemática propicia um novo modelo de racionalidade na formação docente? O objetivo foi refletir e apresentar elementos estruturantes da formação docente a partir do desenvolvimento de uma prática com MM, que foi baseada em uma perspectiva de formação que supera o modelo atual da racionalidade técnica. $\mathrm{O}$ texto segue uma metodologia de pesquisa de natureza qualitativo-interpretativa. Os resultados da reflexão apontam que a MM na perspectiva de Educação Matemática assumida traz em sua concepção elementos potencializadores à superação do atual modelo de formação de professores, em relação à forma de ensinar e aprender Matemática. A atividade revela a importância de o professor vivenciar uma nova maneira de abordar o ensino e de compreender um embasamento teórico, coerente e consistente que seja capaz de dar sustentação à sua prática.
\end{abstract}

Palavras-chave: Modelagem Matemática. Educação Matemática. Ensino e aprendizagem. Educação Básica. Racionalidade crítica.

\footnotetext{
* Professor do Programa de Pós-Graduação em Educação da Universidade Estadual de Ponta Grossa e professor titular aposentado da Universidade Estadual do Centro-Oeste. Doutor em Educação Matemática pela Universidade Estadual de Campinas. Bolsista Pesquisador Sênior pela Fundação Araucária. E-mail: <dioburak@yahoo.com.br>.

** Professora do Instituto Federal do Paraná - Campus Irati. Doutora em Educação pela Universidade Estadual de Ponta Grossa. E-mail: <laynara.zontini@ifpr.edu.br>.
} 


\begin{abstract}
This article discusses the technical rationality in teacher education and the need for a new rationality that addresses the challenges of human formation today, being approached from the assumptions of Mathematical Modeling (MM) in Mathematical Education. To exemplify the discussion, initially theoretical, we present a description and reflection of a practice with MM performed by teachers of Basic Education in a period of 20 hours. The work carried out with the teachers was part of an ongoing training and provided us with research data on Integration and Rural Construction. We analyzed the results of training guided by the question: how does the practice with Mathematical Modeling provide a new model of rationality in teacher education? The objective was to reflect and present structuring elements of teacher education from the development of a practice with $\mathrm{MM}$, which was based on a perspective of formation that surpasses the current model of technical rationality. The text follows a qualitative-interpretative research methodology. The results of the reflection show that MM from the perspective of assumed Mathematical Education brings in its conception potentializing elements to overcome the current model of teacher education, in relation to the way of teaching and learning Mathematics. The activity reveals the importance of the teacher experiencing a new way of approaching teaching and understanding a theoretical, coherent and consistent basis that is able to support their practice.
\end{abstract}

Keywords: Mathematical modeling. Mathematical education. Teaching and learning. Basic Education. Critical rationality.

Resumen: Este artículo discute la racionalidad técnica en la formación docente y la necesidad de una nueva racionalidad que alcance a cumplir los desafíos de la formación humana en la actualidad, siendo abordada a partir de los supuestos de la Modelación Matemática (MM) en la Educación Matemática. Para ejemplificar la discusión, inicialmente teórica, presentamos una descripción y reflexión de una práctica con MM realizada por docentes de Educación Básica en un período de 20 horas. El trabajo desarrollado con los docentes fue parte de una formación continua y proporcionó los datos de investigación sobre el tema de Integración y Construcción rural. Fueron analizados los resultados de la formación orientados por la pregunta: ¿Cómo la práctica con la Modelación Matemática propicia un nuevo modelo de racionalidad en la formación docente? El objetivo fue reflexionar y presentar elementos estructurantes de la formación docente a partir del desarrollo de una práctica con $\mathrm{MM}$, que se basó en una perspectiva de formación que supera el modelo actual de racionalidad técnica. El texto sigue una metodología de investigación de naturaleza cualitativainterpretativa. Los resultados de la reflexión señalan que la MM en la perspectiva de Educación Matemática asumida trae en su concepción elementos potencializadores de la superación del modelo actual de formación docente, en relación con la forma de enseñar y aprender Matemática. La actividad revela la importancia de que el docente pueda vivenciar una nueva manera de abordar la enseñanza y de comprender una base teórica, coherente y consistente que sea capaz de dar soporte a su práctica.

Palabras-clave: Modelación Matemática. Educación Matemática. Enseñanza y aprendizaje. Educación Básica. Racionalidad crítica.

\title{
O modelo da racionalidade técnica e o ensino de Matemática
}

O ensino de Matemática, ao longo das últimas décadas, tem buscado superar a forma usual de se ensinar e aprender Matemática no âmbito escolar, principalmente na Educação Básica. Consideramos que essa forma usual ou tradicional de ensino é aquela centrada em regras, memorizações e com uma abordagem dos conteúdos que enfatiza mais os resultados do que os processos. Nessa forma, as explicações são apresentadas de modo sintético, com destaque nas técnicas; e, após a exposição do conteúdo, o professor faz a resolução de alguns modelos de exercício e solicita aos estudantes a resolução de uma generosa lista de questões que buscam, pela repetição, a aprendizagem dos conteúdos matemáticos.

O modelo de ensino que descrevemos como usual se mantém na escola pela formação tecnicista dada aos professores por décadas, sustentada no âmbito da Racionalidade Técnica. $\mathrm{O}$ modo de ensinar Matemática reflete um modo de produzir conhecimento, chamado por Santos (1988) de pensamento hegemônico e conceituado como o paradigma dominante nas ciências. Trata-se de um modelo de racionalidade que coordena a ciência moderna, "[...] constituiu-se a partir

Práxis Educativa, Ponta Grossa, v. 15, e2014239, p. 1-20, 2020

Disponível em: < https://www.revistas2.uepg.br/index.php/praxiseducativa> 
da revolução científica do século XVI e foi desenvolvido nos séculos seguintes basicamente no domínio das ciências naturais" (SANTOS, 1988, p. 48). O racionalismo moderno é rígido e pautado em ideias matemáticas, na lógica matemática de demonstrações e produção de resultados. Nessa perspectiva, todos os fenômenos observados em um determinado assunto abordado de forma científica devem ser quantificados, e o que não é quantificável é cientificamente irrelevante.

A racionalidade técnica, segundo Duarte et al. (2009, p. 2), “[...] se constitui na base do sistema produtivo capitalista e, assim, é uma das principais ferramentas culturais que moldam as instituições e práticas sociais neste sistema." Sendo a educação uma das principais organizações sociais, é uma das instituições banhadas por essa forma de pensar e agir (DUARTE et al., 2009).

Os modelos de formação de professores mais difundidos, de acordo com Schön (1983), são aqueles relacionados à racionalidade técnica. Esse autor expressa que: "De acordo com esse modelo, também conhecido como a epistemologia positivista da prática, a atividade profissional consiste na solução instrumental de um problema feita pela rigorosa aplicação de uma teoria científica ou uma técnica" (SCHÖN, 1983, p. 21).

De acordo com Carr e Kemmis (1986), essa visão de educação, como uma ciência aplicada, não é nova. Durante o século XIX e início do século XX, muitas pessoas afirmaram que o ensino melhoraria pela aplicação do método científico. Para os autores, o papel da teoria seria iluminar o pensamento dos professores; assim sendo, "[...] a teoria relacionar-se-ia com a prática fornecendo o exame crítico das experiências educacionais práticas” (CARR; KEMMIS, 1986, p. 56).

De acordo com essa visão, a prática educacional deve ser baseada na aplicação do conhecimento científico, e questões educacionais devem ser tratadas como problemas "técnicos", os quais podem ser resolvidos objetivamente por meio de procedimentos racionais da ciência, visando a obtenção de um determinado resultado ou fim. Do mesmo modo, Carr e Kemmis (1986) afirmam que o papel do professor, baseado na visão científica da teoria e prática educacional, é de passiva conformidade com as recomendações práticas dos teóricos e dos pesquisadores educacionais.

Nesse modelo da racionalidade técnica, o professor é visto como um técnico, um especialista que apenas coloca em prática as regras científicas ou pedagógicas que aprendeu durante a sua formação. Desse modo, "[...] para se preparar o profissional da educação, o conteúdo científico e/ou pedagógico é necessário, o qual servirá de apoio para sua prática. Durante a prática, os professores devem aplicar tais conhecimentos e habilidades científicos e/ou pedagógicos" (CARR; KEMMIS, 1986, p. 70). Esse modelo de formação pode sofrer variações, mas tem na racionalidade técnica seu principal embasamento e está associado a pelo menos duas formas de ver e de conceber o ensino de Matemática: concepção platônica da Matemática e a tendência formalista. A concepção platônica usa a sistematização lógica do conhecimento matemático, a partir de definições, de axiomas e de postulados, de teoremas e de corolários. Ela parte da preexistência do conhecimento (inclusive o matemático), como se esse não fosse construído pelo homem, mas, sim, apenas "acordado" dentro dele.

A tendência formalista clássica predominou no Brasil até o final da década de 1950 e pode ser caracterizada pela "[...] ênfase às ideias e formas da Matemática clássica, sobretudo ao modelo euclidiano e à concepção platônica da matemática” (FIORENTINI, 1995, p. 5). Tanto os livros didáticos quanto as aulas seguiam uma ordem de definições, teoremas, demonstrações e exercícios de aplicação; com ênfase no rigor e na formalidade da Matemática. De acordo com Fiorentini (1995, p. 6), em relação ao ensino, nessa tendência temos a grande importância do livro didático, além de ser uma prática centrada "[...] no professor e no seu papel de transmissor e expositor de conteúdos"; quanto ao aluno, sua aprendizagem era passiva e "[...] consistia na memorização e na 
reprodução (imitação/repetição) precisa dos raciocínios e procedimentos ditados pelo professor ou pelos livros". Nessa tendência, o aluno é considerado como uma folha de papel em branco, pronta para receber o conhecimento que deve ser passado pelo professor.

Após 1950, a Educação Matemática brasileira passa por um período de “[...] intensa mobilização em virtude da realização dos cinco Congressos Brasileiros de Ensino de Matemática (1955, 1957, 1959, 1961 e 1966)" (FIORENTINI, 1995, p. 12). Com isso, temos o surgimento da tendência formalista moderna, em um movimento de reformulação e de modernização do currículo escolar conhecido como Movimento da Matemática Moderna (MMM). Segundo Duarte e Silva (2006, p. 88), o MMM “[...] buscava aproximar a Matemática desenvolvida na escola básica com a Matemática produzida pelos pesquisadores da área". Nessa tendência, o ensino continua autoritário e centrado no professor "[...] que expõe/demonstra rigorosamente tudo no quadro-negro" (FIORENTINI, 1995, p. 14), e o aluno continua passivo. Para Fiorentini (1995, p. 14), "[...] essa proposta de ensino parecia visar não à formação do cidadão em si, mas à formação do especialista matemático".

O MMM buscou realizar uma mudança curricular com a unificação dos campos da Matemática, tendo como elementos unificadores a teoria dos conjuntos, as estruturas algébricas e a teoria de funções. Essa tendência mostra-se alinhada ao pensamento moderno, predominante ainda nas ciências nesse período. Outra característica é a ênfase nos aspectos estruturais e lógicos da Matemática; quando o ensino deveria refletir o espírito da Matemática contemporânea que, graças ao processo de algebrização, tornou-se mais poderosa, precisa e fundamentada logicamente.

Na concepção da Matemática Moderna, segundo Fiorentini (1995), a dimensão formativa sob a perspectiva da Matemática era a apreensão da estrutura subjacente, mais importante do que a aprendizagem de conceitos e as aplicações. Dessa forma, aprender Matemática seria, em última instância, apreender suas estruturas.

No início dos anos de 1970, nos Estados Unidos, muitas críticas a esse Movimento já se faziam presentes. O livro de Morris Kline, intitulado O fracasso da Matemática Moderna, publicado no Brasil em 1976, além das críticas ao MMM, evidenciou o declínio dessa Matemática, em âmbito escolar, principalmente nos níveis de ensino denominados Educação Básica. A Educação Básica é o primeiro nível do ensino escolar brasileiro e compreende três etapas: a Educação Infantil, o Ensino Fundamental e o Ensino Médio.

Para alguns educadores matemáticos, o fracasso do MMM deu-se pelo despreparo dos professores para a compreensão mais efetiva da proposta. A ênfase nas ideias foi substituída por uma ênfase apenas na simbologia. No Brasil, ensejou descontentamento principalmente dos professores do $1^{\circ}$ e $2^{\circ}$ Graus à época (equivalente hoje ao Ensino Fundamental e Médio), pois não parecia haver entre eles preocupações maiores, quer com o ensino, quer com a aprendizagem da Matemática, cuja ênfase era posta na simbologia e na estrutura, muito mais do que nas ideias.

Essas duas formas de racionalismo, clássico e moderno, nas formas de abordar o ensino de Matemática, constituem os exemplos mais representativos do modelo da racionalidade técnica que direcionou e ainda direciona a formação dos professores e orienta a sala de aula pela forma de atuação dos professores que ensinam Matemática. Para Brandt e Tozetto (2009, p. 75), “[...] a cultura formativa promovida na Universidade relaciona-se diretamente com as formas de investimento na profissão e com os alunos da Licenciatura em Matemática no sentido de levá-los a não se sentirem professores de matemática, mas sim 'um matemático que ensina matemática"'; desse modo, a Universidade ainda mantém uma formação pautada na racionalidade técnica, marcada pelo MMM. 
Como decorrência, a racionalidade técnica pode ser considerada como um fator que impõe condicionantes à prática pedagógica, que a tornam acrítica devido à mecanização do trabalho docente. Outra característica da racionalidade técnica em âmbito educacional, segundo Pimenta (2002), resulta em um controle cada vez mais burocrático da escola e do trabalho do professor.

Para Duarte et al. (2009, p. 3), “[...] os atuais cursos de formação de professores impõem saberes em um movimento de reforma de ensino moldados pela racionalidade técnica". Essa concepção de formação é responsável pela dificuldade de mudar o ensino, por não levar em conta os saberes dos professores, sua experiência e o contexto no qual eles ensinam (VILLANI; FREITAS, 2002 apud DUARTE et al., 2009). Os autores asseveram que “[...] inversamente do que poderia ser esperado, esta imposição provoca resistência à mudança, o que impede, na maioria das vezes, que os professores busquem soluções para os problemas do ensino" (DUARTE et al., 2009, p. 3). Professores formados por essa racionalidade buscam nas formações modelos que possam ser reproduzidos em sala de aula e que resolvam os problemas de aprendizagem.

Segundo Macenham, Tozetto e Brandt (2016, p. 508), os professores deveriam participar de modo intenso da constituição dos saberes docentes; no entanto, muitas vezes eles "[...] mantêm o papel de transmissores e não de produtores dos direcionamentos de seu trabalho". Para as autoras, esses saberes abrangem as experiências do professor e, também, o conhecimento que ele possui sobre os conteúdos e como ensiná-los.

Para Morin (2000), estamos vivendo em um momento de mundialização, em que os problemas locais se tornam globais, assim como os problemas globais se tornam locais, mas organizados por uma extrema disciplinarização. Vivemos em uma realidade multidimensional, mas buscamos compreendê-la de forma unidimensional; herdamos também uma concepção linear da causalidade, que nos restringe a enxergar outras formas de causalidade, como a cíclica e a retroativa (MORIN, 2000). Assim, o autor aponta para a necessidade de uma nova racionalidade que oriente os sujeitos, a formação humana e essencialmente a formação docente e a organização escolar.

\section{A Educação Matemática no caminho de uma nova racionalidade}

Diante da compreensão dos problemas globais, “[...] desenvolver autonomia, cooperação e criticidade são habilidades fundamentais em um mundo que está permanentemente evoluindo" (ROCHA, 2014, p. 120). Por isso, vislumbramos a necessidade de buscar uma nova racionalidade que oriente a formação docente.

A partir das reflexões sobre a racionalidade técnica, percebemos a urgência de modificar o modo de compreender o ensino da Matemática. Segundo Caldeira (2009, p. 34), "[...] hoje, o que se pretende, dentro ou fora da escola, é uma racionalidade sustentada por uma forma não mais sobre os pilares do determinismo e das verdades imutáveis, mas aquela baseada em pressupostos do pensamento sistêmico e da complexidade". O que se propõe para contrapor a racionalidade técnica é a racionalidade crítica como orientadora da formação humana. De acordo com Carr e Kemmis (1986, p. 38), as visões técnica e prática não são muito distintas no que tange à educação, pois: "De um lado, professores desejam enfatizar os objetivos complexos da educação contemporânea, os quais requerem habilidades sofisticadas e conhecimento técnico sobre métodos de ensino. De outro, eles querem enfatizar sua autonomia como profissionais, o que requer deliberação prática".

No modelo da racionalidade crítica, a educação é historicamente localizada, acontece contra um pano de fundo sócio-histórico e projeta uma visão do tipo de futuro que nós esperamos construir. Para Carr e Kemmis (1986), educação é uma atividade social, com consequências sociais, 
não apenas uma questão de desenvolvimento individual, intrinsecamente política, o que afeta as escolhas de vida daqueles envolvidos no processo; e também problemática.

Segundo Macenham, Tozetto e Brandt (2016, p. 505), “[...] os saberes docentes originam tanto dos cursos de formação de professores quanto de suas experiências pessoais e profissionais"; por isso, a importância de considerar as práticas para a formação de professores. Assim, para uma forma diferente de se fazer o ensino da Matemática, torna-se necessário romper o paradigma que sustenta e embasa esse modelo, ainda atual, de se fazer o ensino. Isso também perpassa uma responsabilidade para a superação desse modelo nas instituições formadoras desses professores, enfaticamente em relação aos formadores, que atuam na formação inicial e continuada. Para Macenham, Tozetto e Brandt (2016, p. 510-511), “[...] os processos de formação capazes de instigar os professores à reflexão demonstram preocupação com a preparação de sujeitos protagonistas, pelo seu próprio desenvolvimento profissional e para a constituição dos saberes docentes".

Compreendemos que a Educação Matemática emerge da própria Matemática, inicialmente como uma preocupação dos matemáticos sobre como ensinar essa disciplina nas universidades. $\mathrm{O}$ movimento histórico de crescimento da Educação Matemática na qualidade de ciência se mostra como um marco no ensino da Matemática, em uma transição da forte presença da racionalidade técnica, própria da Matemática, para uma nova racionalidade ligada à Educação.

Os novos estudos realizados com o advento do Movimento Educação Matemática, nos anos de 1970, trouxeram novas perspectivas para o ensino da Matemática. Mesmo se constituindo como disciplina, a Educação Matemática permanece em movimento, buscando se estabelecer epistemologicamente, construindo suas teorias que, mesmo com diferentes pontos de vista, tem como foco ensinar e aprender matemática.

Os diversos estudos já realizados em relação à Educação Matemática permitiram-nos fazer uma opção pela forma de concebê-la. Tal opção deve-se ao fato de a Educação Matemática possuir toda uma história que, ao mesmo tempo que mostra sua origem, também mostra as formas de olhá-la; destacamos aqui ao menos duas. A primeira forma de olhar dá-se pela sua trajetória histórica na transição dos séculos XIX para o século XX, tendo com um dos seus precursores John Dewey (1859-1952), com sua obra denominada Psicologia do Número (1895), na qual propunha uma relação cooperativa entre professores e alunos, assim como "[...] a integração entre todas as disciplinas" (D’AMBROSIO, 2006, p. 11). A outra forma é sobre sua natureza que pode ser considerada um novo constructo científico para ensinar e aprender a Matemática, principalmente na Educação Básica.

Ainda nessa trajetória, o matemático americano Eliakim H. Moore (1862- 1932), segundo D’Ambrosio (2006), escreveu um artigo propondo a integração da Matemática com a Física em um sistema de instrução permanente, que deve acontecer em um laboratório com o objetivo de desenvolver o espírito de pesquisa. Outros matemáticos também deram contribuições nesse sentido, como o casal Grace C. e Willian H. Young, conforme D'Ambrosio (2004), que propuseram “[...] trabalhos manuais, o concreto auxiliando o ensino de geometria abstrata". Para D'Ambrosio (2004, p. 71), o passo mais importante para a Educação Matemática se estabelecer como disciplina foi dado graças à contribuição de Felix Klein (1849-1925), com o livro intitulado Matemática elementar sob o ponto de vista avançado, em 1908.

Como constituição de uma subárea da Matemática e da Educação, a Educação Matemática consolidou-se em 1908, no Congresso Internacional de Matemáticos, ocorrido em Roma, com a fundação da Comissão Internacional de Instrução Matemática - conhecida pelas siglas IMUK/ICMI - liderada por Felix Klein, tendo como veículo de divulgação a revista L'Enseignement Mathématique (D'AMBROSIO, 2004). Outros fatos marcantes para um novo viés

Práxis Educativa, Ponta Grossa, v. 15, e2014239, p. 1-20, 2020 Disponível em: < https://www.revistas2.uepg.br/index.php/praxiseducativa> 
do que se pretendia com a Educação Matemática acontecerem com a justa preocupação emergente com o ensino da Matemática e foram: a fundação da Mathematical Association of America (MAA), em 1915, direcionada para o Ensino Superior; e, em 1920, o National Council of Teachers of Mathematics (NCTM), destinado ao ensino secundário e elementar (D'AMBROSIO, 2006).

Após a Segunda Guerra Mundial, houve um significativo desenvolvimento do que se denominava Educação Matemática, com propostas de renovação curricular embasadas em teorias de estudiosos renomados, dentre os quais se destaca Jean Piaget. Em 1951, foi criado, nos Estados Unidos, o projeto University of Illinois Commitee on School Mathematics, com repercussão internacional e sob a liderança de Max Bieberman. Além disso, nessa década, em 1958, surgiu o School Mathematics Study Group (SMSG), na Stanford University, sob a liderança de Edward G. Begle. Esse projeto viria a ter a maior repercussão de todos, e passou a ser identificado com o que ficou conhecido como New Math (D'AMBROSIO, 2004).

O espírito renovador da Matemática verificado nos últimos 150 anos e a atuação de eminentes matemáticos acabou por, em vez de revolucionar os processos relativos ao ensino, à aprendizagem e ao conhecimento do sujeito que aprende, consolidar a partir dessa década de 1950, uma mudança no âmbito da própria Matemática, construindo uma nova racionalidade.

Apenas nos anos de 1980, dá-se o nosso segundo olhar à Educação Matemática, quando, na legítima preocupação com o ensino de Matemática, começa a ser retomada, com Higginson (1980), a busca por conhecer mais sobre a natureza da Educação Matemática, motivada pela questão: O que de mais significativo, além da Matemática existe na Educação Matemática? Os avanços sobre a natureza da disciplina Educação Matemática são creditados à Higginson (1980) que, em documento mimeografado, intitulado On the foundations of Mathematics Education ${ }^{1}$, escreve um artigo após questionar sobre o motivo de que

[...] decorridos um quarto de milênio, os educadores matemáticos ainda estão no estágio de procurar por metodologias apropriadas e reclamando da "perversidade" de rapazes e moças contemporâneos, que parecem encontrar na matemática "boluses", ou pílulas, muito difíceis de engolir também? (HIGGINSON, 1980, p. 3, tradução nossa).

Higginson expõe três pressupostos, os quais ele considera imprescindíveis e estão relacionados à natureza, ao objetivo e à eficácia da Educação Matemática subjacente às observações que se seguem:

\begin{abstract}
I: existem indivíduos que têm, como uma parte significativa de sua responsabilidade profissional, a consideração e ações sobre questões relacionadas à aquisição de conhecimento matemático. Esses indivíduos, cujos números incluem sala de aula Professores, escritores de currículos, educadores de professores e Pesquisadores, são "educadores de matemática" e a Disciplina que abrange suas preocupações profissionais é a "educação matemática";

II: o objetivo de um educador matemático é aperfeiçoar, tanto do ponto de vista intelectual como do emocional, a experiência de aprendizagem do estudante;

III: a experiência de aprendizagem de matemática para a maioria dos estudantes não foi intelectual nem emocionalmente satisfatória; sua exposição à matemática não foi prazerosa, nem a fez mais competente. (HIGGINSON, 1980, p. 3, tradução nossa).
\end{abstract}

\footnotetext{
1 "Why is it that, after more than a quarter of a millennium, mathematics educators are still at the stage of searching for the appropriate methodological "composition" and complaining of the "perverseness" of contemporary lads and lasses who seem to find their mathematical "boluses", or pills, quite hard to swallow too?" (HIGGINSON, 1980, p. 3).
} 
Para o autor, o fundamental e que justifica o pequeno avanço relativo às questões do ensino, e como implicação, da aprendizagem, é a convicção de que nós temos uma visão excessivamente estreita dos fatores que influenciam a nossa disciplina. Nesse sentido concordamos com Higginson (1980) quando afirma que temos falhado em criar teorias coerentes, ou metodologias em Educação Matemática, em grande parte porque ignoramos alguns aspectos essenciais de seus fundamentos.

Ao fazermos uso do termo ensino e aprendizagem de forma explícita, parece que ele se vincula de forma indelével à Educação Matemática, assim como explicitado por Baldino (1991, p. 51), “[...] pois educação lembra 'pedagogia', lembra 'aprendizagem', lembra, ainda, interesse e motivação e, suas ações envolvem o campo do sujeito situado no contexto social".

Um ponto a ser ressaltado é que o MMM foi considerado por muitos pesquisadores e educadores como um Movimento de Educação Matemática. Entendemos que isso se fez no estrito sentido comum de entender que, onde se efetua ensino de Matemática, existe relação e ocorre "Educação Matemática". Esse entendimento precisa ser bem explicitado para prover compreensão das diferenças que se fazem presentes nas formas de conceber esses movimentos. É o que nos propomos ao ensejar as discussões sobre a Educação Matemática, mais precisamente sobre a sua natureza e sua metodologia, tais quais se apresentaram anteriormente no âmbito da Matemática Moderna.

Por isso, destacamos que a Educação Matemática tem como objeto de estudos não a Matemática propriamente dita, mas os problemas decorrentes das relações de ensino e de aprendizagem dessa ciência que se fazem presentes no ato educativo. Em nosso entendimento, só se justifica o uso da expressão "Educação Matemática" quando se leva em consideração e se compreende a natureza própria da relação ostensiva da Educação-Matemática.

O trabalho de W. Higginson (1980) contribuiu para explicitar as áreas a que se refere Wain (1978 apud RIUS, 1989) e que se constituem como integrante da natureza da Educação Matemática. Trata-se do Modelo do Tetraedro de Higginson (Figura 1), cujas faces seriam constituídas pela Matemática, Filosofia, Psicologia e Sociologia, e que foi denominado MAPS.

Figura 1 - Tetraedro de Higginson

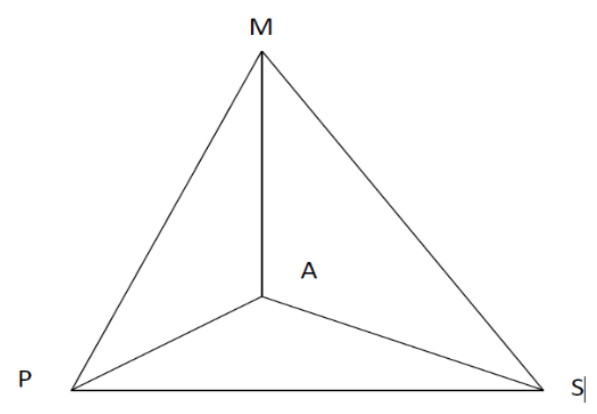

Fonte: Burak (2017, p. 13).

Nessa figura, cada disciplina corresponde a uma face do tetraedro. Para Higginson (1980), essas disciplinas são necessárias e suficientes para definir a natureza da Educação Matemática naquele momento. Esse modelo, atualmente, já está defasado pela própria dinâmica da Educação Matemática e pelo avanço de novos estudos dessas componentes iniciais. Além disso, pela incorporação de outras áreas, pode-se dizer que se constitui um novo constructo científico capaz de dar sustentação ao processo de ensino apropriado de proporcionar aprendizagem. As disciplinas do tetraedro dizem respeito às seguintes perguntas: 
(1) O quê? Que corresponde, basicamente, à dimensão da Matemática.

(2) Quando? E Como? Que correspondem à Psicologia.;

(3) Por quê? Concernente à dimensão da Filosofia.;

(4) Quem? E Onde? Como questões que remetem à dimensão da Sociologia.

Para Higginson (1980), os vértices e as arestas constituem as confluências das disciplinas que compõem o tetraedro e, assim, a aresta MA corresponde aos interesses da Filosofia e da Matemática, por exemplo. Na aresta MP, confluem os interesses da Matemática e da Psicologia.

O modelo do tetraedro foi fruto de um momento histórico, conforme esclarecido pelo próprio Higginson (1980), e poderia tornar-se obsoleto com o passar do tempo. Isso de fato está ocorrendo e trazendo significativas contribuições para a natureza da Educação Matemática. Para Burak e Klüber (2008), na atualidade, outras áreas do conhecimento já se constituem com uma grande contribuição à Educação Matemática, tais como a Antropologia, a Sociologia, a Linguística, a Língua Materna e a História da Matemática, entre outras.

Os estudos de Burak e Klüber (2008), em relação à natureza da Educação Matemática que permitiram essa nova configuração, estão embasados na característica dinâmica da própria área, que, ao realçar a importância da língua materna para a comunicação e as funções discursivas, a epistemologia do pensamento complexo, possibilita uma visão mais ampla do assunto em estudo. Diante disso, os autores buscaram representar momentaneamente uma configuração que explicita as inter-relações que fundamentam a Educação Matemática, tal como vemos na Figura 2.

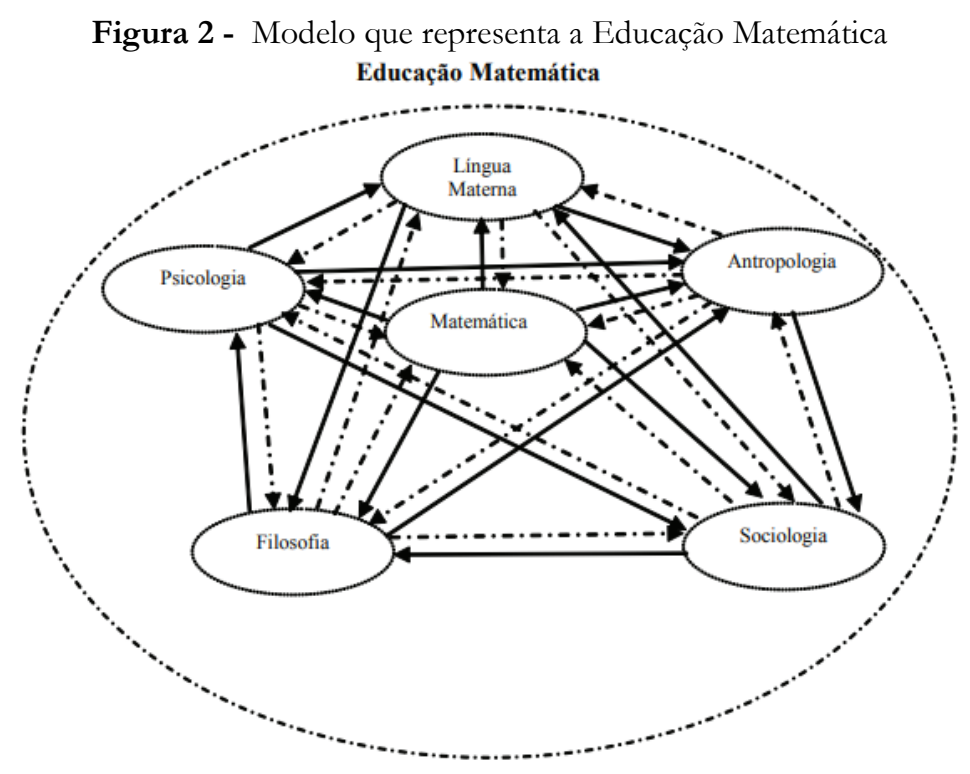

Fonte: Burak e Klüber (2008, p. 98).

As flechas na figura indicam as interações entre a Matemática e as diferentes áreas, assim como as áreas entre si, reforçando que cada uma tem importante contribuição para a Educação Matemática. O modelo aponta uma configuração tal que expressa a relação entre a Matemática com outras áreas da Educação, superando a configuração inicial. Assim sendo, essa configuração tornase imperativa, necessária mesmo para embasar a forte vinculação da Matemática e seus métodos de construção como área de conhecimento e o conhecimento orientado pelas áreas das Ciências Humanas e Sociais, que dão sustentação ao processo de ensino e aprendizagem, principalmente da 
Matemática no âmbito da Educação Básica. Há uma interação entre a Matemática e todas as demais áreas que com ela se relacionam reciprocamente.

Nesses termos, essa representação da Educação Matemática reflete uma visão da Matemática como um componente sobremaneira importante em âmbito escolar, mas não é mais vista como "o componente". A percepção da Matemática como parte do todo, e não como o todo em si, promove novos enfoques e gera a possibilidade de se estabelecer interações importantes. Confere, sobretudo, a possibilidade de se tratar a Matemática e seu ensino e aprendizagem em um contexto em que se favorecem as múltiplas interações entre as áreas que a constituem, as quais, por sua vez, agem e interagem em uma relação de reciprocidade (BURAK; KLÜBER, 2008). Nessa perspectiva, segundo Petraglia (2005), reconhece-se e trabalha-se com a complexidade na busca:

\footnotetext{
De um 'ser' e do 'saber' uno e múltiplo que nos revela uma ciência que, mais do que a detentora de verdades absolutas e imutáveis, nos aponta para um caminho de novas descobertas e novas verdades que aceitam a complexidade como uma realidade, em que o ser humano é ao mesmo tempo sujeito e objeto de sua própria construção e do mundo. (PETRAGLIA, 2005, p. 13).
}

Nessa perspectiva da Educação Matemática que ora assumimos, concordamos com o pensar de Morin (1980 apud PETRAGLIA, 2005) de que cada indivíduo é sem igual e singular na sua anatomia, na sua fisiologia, no seu comportamento e na sua inteligência, ainda que apresente, muitas vezes, semelhanças raciais, étnicas, sociais e culturais. Assim sendo, como cada ser é único e original, é a sua individualidade que o distingue dos demais, na existência de si mesmo. Ainda nesse sentido, Morin (1980 apud PETRAGLIA, 2005) esclarece aspectos importantes sobre "ser sujeito". Para ele, o sujeito é o "eu" que se coloca no centro do mundo, ocupando seu próprio espaço. Sua concepção é complexa, por isso o "eu" precisa da relação com o "tu" para ambos pertencerem ao mundo.

Para Morin (2003, p. 63), “[...] a educação deve contribuir para a autoformação da pessoa (ensinar a assumir a condição humana, ensinar a viver) e ensinar como se tornar cidadão". O autor também considera que "[...] um cidadão é definido, em uma democracia, por sua solidariedade e responsabilidade em relação a sua pátria” (MORIN, 2003, p. 63). Dessa forma, somos verdadeiramente cidadãos "quando nos sentimos solidários e responsáveis” (MORIN, 2003, p. 73).

O sujeito emerge, ao mesmo tempo que o mundo, a partir de sua auto-organização, que é a capacidade que o ser humano tem de transformar-se sempre. Essa capacidade envolve outras características para o desenvolvimento do processo auto-organizador, como a individualidade, a incerteza, a ambiguidade e a complexidade (PETRAGLIA, 2005). Assim, compreendemos que ao ensinar Matemática devemos estar preocupados com a formação dos cidadãos e não apenas com o domínio de algoritmos e procedimentos de cálculo. Por isso, visualizamos na Educação Matemática os pressupostos necessários para a prática docente do professor que ensina Matemática, preocupado com que o estudante aprenda os conteúdos matemáticos importantes para a sua ação em sociedade.

\section{A Modelagem Matemática na Educação Matemática}

$\mathrm{Na}$ expectativa da superação do paradigma que preside a ciência moderna, que se tornou referencial na formação do professor e, em consequência é reproduzido, em maior ou menor escala, pelos professores sob esse modelo de formação, admitimos que, se uma transformação na educação acontecer, deverá ser para valorizar a sala de aula, a formação de um sujeito capaz de enfrentar os desafios deste século. 
É nessa perspectiva e sob a égide dos fundamentos da Educação Matemática que encorajamos a busca por uma nova racionalidade, seja na formação inicial ou continuada de professores para a Educação Básica, ou outro nome que se der a essa forma de formação. A Educação Matemática apresenta um novo constructo científico capaz de prover não somente uma prática docente diferenciada, mas também possibilitar uma aprendizagem com mais sentido e significado para os estudantes. Para isso, é importante o professor em formação, seja ela inicial ou continuada, conhecer os métodos e os fundamentos teóricos e epistemológicos capazes de possibilitar conhecimento sobre o conteúdo a ser ensinado e também sobre as várias formas de abordagem desse conteúdo. Segundo Klüber e Burak (2012, p. 480), os professores de Matemática da Educação Básica geralmente não participam de núcleos de pesquisa de Modelagem Matemática, por isso acabam sendo "[...] impelidos a realizarem investigações mais voltadas à verificação e à confirmação de resultados da literatura sobre o tema".

Dentre as tendências da Educação Matemática, a Modelagem Matemática, quando na concepção da Educação Matemática, conforme tratada neste texto, apresenta elementos capazes de realizar um ensino com vistas às muitas aprendizagens em sala de aula. Com isso, também ressaltamos a importância de se trabalhar com essa metodologia nos diversos momentos da formação docente.

Torna-se necessário e conveniente expressar nosso entendimento sobre a Modelagem Matemática em uma perspectiva da Educação Matemática, que se pauta pela Matemática e pelos fundamentos das Ciências Sociais e Humanas, de característica interdisciplinar cujo objetivo é possibilitar um ensino de Matemática com vistas à aprendizagem. Esse entendimento torna-se imprescindível, notadamente quando se trata da Educação Básica, cujo objetivo primeiro é a construção do conhecimento matemático pelos estudantes e não a preocupação com a aplicação desses conhecimentos, que, nesse nível de escolaridade, ainda estão sendo construídos.

Na concepção de Modelagem como metodologia de ensino, tendo como balizadora a perspectiva de Educação Matemática, embora se reconheça os valorosos esforços de outros pesquisadores, assumimos a concepção de Burak (2004, 2010). Nessa forma de conceber a Modelagem, segundo Burak (1992), o trabalho parte dos seguintes princípios: 1) Partir do interesse do grupo ou dos grupos de pessoas envolvidas; 2) Obter as informações e os dados, sempre que possível, onde se localiza o interesse do grupo ou dos grupos.

A Modelagem Matemática, na perspectiva de Burak (2004), tem como princípio o interesse do estudante, mais especificamente do grupo, e, para fins de encaminhamentos do trabalho ou das atividades na sala de aula, Burak (2004) sugere à Modelagem Matemática cinco etapas flexíveis: 1. Escolha do tema; 2. Pesquisa exploratória; 3. Levantamento do(s) problema(s); 4. Resolução do(s) problema(s) e o desenvolvimento de conteúdos relacionados ao tema; e 5. Análise crítica da(s) solução(ões).

De acordo com Burak (2010, p. 5), essa forma de pensar o ensino da matemática “[...] carrega consigo a concepção de uma matemática não restrita ao seu próprio contexto, mas capaz de relacionar o que é aprendido dentro e fora da escola: uma matemática construída na interação do homem com o mundo, uma matemática com história". Com esses esclarecimentos teóricos, avançamos no texto apresentando os dados de uma formação de professores orientada pela e para a prática com Modelagem Matemática, conforme Burak (2004), com o intuito de explicitar a emergência da nova racionalidade na formação docente. 


\section{Relato de experiência: um curso com professores e uma prática com modelagem}

Esta formação envolveu professores da Educação Básica, estudantes em formação inicial e da Pós-Graduação, e teve a duração de 20 horas. Foi realizada durante um curso de formação continuada em práticas com Modelagem Matemática.

As formações em Modelagem, sejam elas inicial ou continuada, devem favorecer a vivência de todas as etapas segundo Burak (1992), conforme as condições possíveis. Assim, para esse curso, tínhamos à disposição um laboratório de informática, a biblioteca da instituição e a sala de aula. Vale ressaltarmos uma característica do público-alvo da formação: os familiares de muitos deles eram pequenos agricultores. Nesse contexto, algumas temáticas tendem a emergir com mais facilidade, como as construções, que são atividades com as quais se deparam constantemente. Assim, essa prática foi desenvolvida por professores da Educação Básica², sob a supervisão do professor pesquisador com o tema "Construções Rurais".

Como a maioria dos professores participantes, e também de seus estudantes, eram filhos de pequenos agricultores, o direcionamento do tema recaiu na criação de frangos. Essa criação é feita por um sistema chamado "Integração", por isso focaram em construções que estão de acordo com esse sistema. A ideia inicial que justificou a escolha do tema foi que essa atividade poderia suprir algumas necessidades financeiras da maioria das famílias durante o período entre o plantio e a colheita de produtos agrícolas. As discussões iniciais focaram os espaços nas propriedades para a construção de um barracão para a criação de frangos de corte para uma determinada empresa da região Sudoeste do Paraná.

Como se tratava de um barracão para a produção de frangos de corte, precisava-se conhecer inicialmente qual o espaço disponível na propriedade, pois, a partir do espaço disponível, poderse-ia definir: Qual a quantidade de frangos a serem criados? Qual a quantidade de frangos por metro quadrado? Essas e outras questões levaram o grupo a várias discussões, que também ensejaram a busca de mais informações.

Por conta da forma de conceber a Modelagem, os professores foram incentivados a pesquisar e buscar dados em sites, em conversas entre os participantes do grupo e também com participantes de outros grupos, agentes dos órgãos da Secretaria da Agricultura do município ou de outros órgãos, ou, ainda, nas empresas especializadas nesse tipo de atividade. Pela temática, era importante responder questões como: Qual o espaço da propriedade destinado à criação de frangos? Ela deve atender algumas normas quando se trata de Consórcio ou Integração com empresas? Quais são essas normas? Todas essas ações ensejaram simultaneamente interações entre os componentes do grupo e entre os componentes dos diversos grupos.

$\mathrm{Na}$ busca de desenvolver uma nova racionalidade na formação de professores, é importante que se incentive o professor a buscar os dados, seja por meio de literatura sobre o assunto, seja por meio de sites, seja por meio de entrevistas no âmbito das empresas que desenvolvem essa forma denominada Integração. Essas formas de interação são incentivadas também nas conversas entre os grupos constituídos de três a quatro participantes. A Modelagem Matemática, na perspectiva de Educação Matemática assumida, coloca-se como uma possibilidade de promover uma nova forma de racionalidade que supere o tradicional modelo de formação de professores, quando os tornam protagonistas das ações vivenciadas.

Essa etapa de busca de dados corresponde, na forma concebida da Modelagem Matemática, à segunda etapa, a da pesquisa exploratória. Essa etapa reveste-se de importância para desenvolver

\footnotetext{
2 Parte dessa prática foi desenvolvida com estudantes do $9^{\circ}$ ano do Ensino Fundamental.
} 
no professor em formação, e posteriormente nos estudantes, a capacidade de obter dados pelos multimeios disponíveis. Desenvolve a capacidade de saber procurar e buscar diferentes fontes de informação. Quando esses dados forem coletados por meio de uma entrevista, desenvolve-se também a capacidade de expressão e de comunicação, pois exige um direcionamento das questões, clareza na formulação e, principalmente, na forma de expressar a questão ou as questões. Tanto na formação continuada, como na formação inicial, essa etapa favorece a curiosidade, que é importante na formação de um espírito investigativo dos nossos professores e com possibilidades de influenciar, também em aula, os estudantes.

Após algumas discussões promovidas diante dos dados coletados em sites, em conversas com agentes do órgão municipal e estadual, com os pais e vizinhos em relação à quantidade de frangos por metro quadrado, chegou-se ao número que é entre 10 a 15 aves por $\mathrm{m} 2$. Esses valores podem variar dependendo de alguns fatores como temperatura da região e espaço físico. Ainda durante a etapa da pesquisa exploratória, descobriram que as propriedades deveriam cumprir algumas normas das empresas compradoras do produto.

Para a definição de um espaço, foi utilizada a propriedade da família de um dos professores participantes, uma propriedade com área de aproximadamente seis hectares. Para saber mais informações sobre o terreno, o grupo, cujo pai de um dos participantes era proprietário, foi até o local para a medição, pois apenas o desenho do espaço não era suficiente para uma adequada compreensão do local. Assim, conheceram o espaço cujas medidas eram: profundidades $=16$ metros e 20,5 metros; uma das larguras era muito próximo de 8 metros, e a outra, 5 metros. Os lados contíguos de 16 metros e 8 metros formavam um ângulo muito próximo de $90^{\circ}$. Para essa medição, foi utilizada uma trena de 5 metros. Com base nos dados trazidos por esse grupo de professores, os demais grupos elaboraram um primeiro esboço do terreno (Figura 3).

Figura 3 - Esboço do terreno

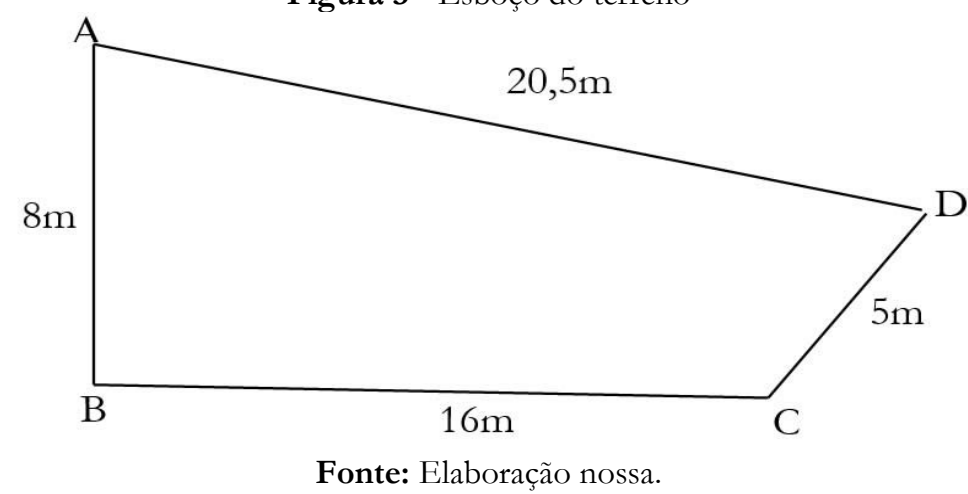

A definição da quantidade de frangos por metro quadrado e do local disponível para essa possível construção foram atividades comuns para todos os grupos.

A partir do esboço da forma do terreno, teve início, entre os grupos, discussões sobre qual a área do terreno e qual o espaço do terreno seria ocupado para a construção do galpão ou barracão. Desse debate, algumas questões emergiram, por exemplo: Como calcular a área de uma figura que representa um terreno que era irregular? Será que as propriedades das figuras regulares se mantêm nas figuras irregulares? Quais se mantêm, quais são alteradas? Essas discussões sobre as possíveis questões levantadas após a pesquisa exploratória na concepção de Modelagem na Educação Matemática constituem a etapa 3, denominada Levantamento do(s) problema(s), e ensejaram outras ações: buscar conhecer as propriedades das figuras regulares em relação ao comprimento dos lados, em relação à medida dos ângulos internos, entre outras. 
Em meio às discussões, alguns participantes, cujos pais ou familiares são pequenos agricultores, disseram que estes tinham uma forma particular para calcular a área de uma figura irregular. Entretanto, os professores não tinham clareza, pois nunca haviam utilizado essa forma de cálculo na escola, uma vez que os livros apresentam, na maior parte dos casos, as figuras de formas bem definidas, como: triângulo, retângulo, paralelogramo, trapézio e quadrado. Em sua prática docente, poucas vezes haviam se deparado com situações diferentes das que constam em livros didáticos.

O cálculo da área da superfície foi muito interessante e constitui, no processo da Modelagem, a etapa da resolução do(s) problema(s), um momento que os conteúdos matemáticos utilizados têm importância e significado. Em conversa com alguns agricultores que tiveram necessidade de resolver questão similar àquela dos participantes em suas atividades do dia a dia, como plantar milho, feijão ou outra cultura, soubemos que eles procediam da seguinte forma: "Somavam as duas larguras e dividiam por dois, somavam as profundidades e dividiam por dois"; desse modo, transformavam a figura em um retângulo em que as medidas do comprimento e largura eram as médias aritméticas das medidas dos lados opostos. Dessa forma, a Figura 3 ficaria transformada em um retângulo A'B'C’D' (Figura 4).

Figura 4 - Retângulo ABCD

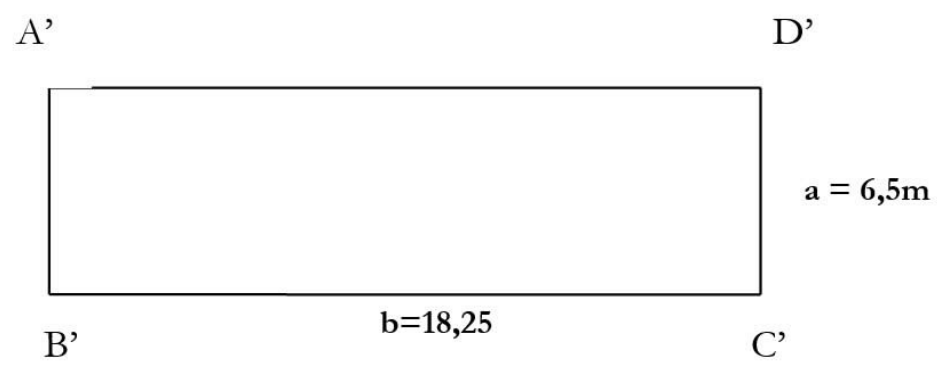

Fonte: Elaboração nossa.

Muitas vezes, essa atividade do cálculo de área mais formal, mediado pela utilização das fórmulas, pode ser precedida por exercícios que envolvem completar o plano. Esse trabalho vai resultar em algumas etapas até que o estudante tenha a compreensão de que a área da superfície de uma forma de retângulo ou quadrado é dada pelo produto do número de quadrados para preencher o lado a pelo número de quadrados para preencher o lado b.

No entanto, se o trabalho for realizado futuramente em turmas nas quais os seus estudantes já conhecem a expressão da área de um retângulo, basta utilizá-las buscando consolidar o conceito. Frequentemente, o trabalho da MM parte da estratégia empírica para a formal. No caso aqui apresentado, partiu-se para o cálculo da área da superfície do retângulo construído A'B'C'D'. Assim, o cálculo da área da superfície em questão $S A^{\prime} B^{\prime} C^{\prime} D^{\prime}=\left(A^{\prime} B^{\prime}\right)$. (A'D') ou a. b , em que a $=6,5 \mathrm{~m}$ e b $=18,25 \mathrm{~m}$ é SA'B'C'D $=6,5 \mathrm{~m} \times 18,25 \mathrm{~m}=118,62 \mathrm{~m} 2$

$$
\text { (I) } \mathrm{SA}^{\prime} \mathrm{B}^{\prime} \mathrm{C}^{\prime} \mathrm{D}^{\prime}=118,62 \mathrm{~m} 2
$$

A segunda hipótese levantada deu-se durante a etapa que, na Modelagem, se denomina análise crítica da solução e teve início com a discussão de que poderia haver diferença entre as áreas das superfícies calculadas dessa forma e a área "real". Novas ações com o propósito de buscar um resultado que fosse mais confiável favoreceram várias formas de interação entre os grupos, sempre nesse caso, as interações consideradas com objetivo de aprendizagem. Assim, uma segunda 
hipótese discutida e aprovada foi tentar "dividir" a figura irregular em formas conhecidas pelos participantes para o cálculo da área da superfície (Figura 5).

Figura 5 - Divisão da figura irregular

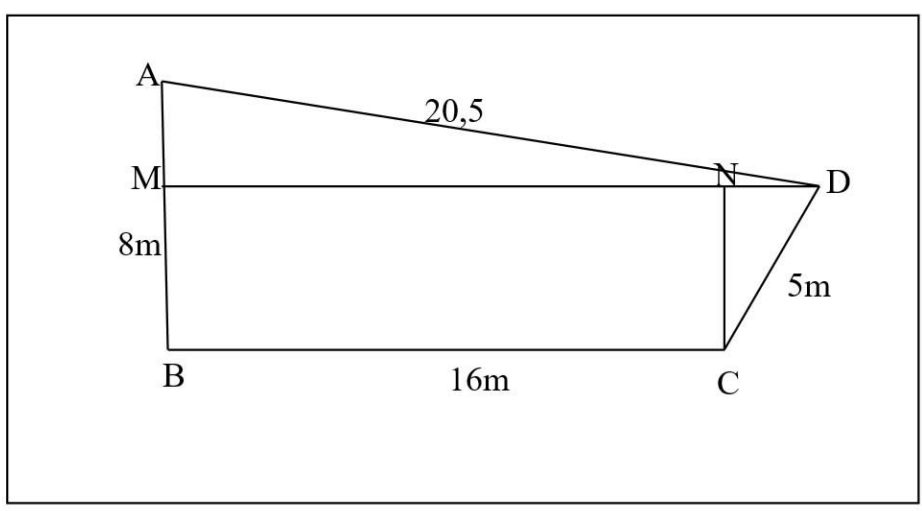

Fonte: Elaboração nossa.

A Figura 5 ficou decomposta em três partes: triângulo retângulo AMD, retângulo MBCN e triângulo retângulo $\mathrm{CND}$, por construção. É importante realizar essas construções em papel milimetrado, pois podem ser necessárias medidas de ângulos e comprimentos, com alguma precisão. Nesse caso, a área da superfície da figura ABCD é igual à somadas áreas das superfícies:

$$
\mathrm{SABCD}=\mathrm{SAMD}+\mathrm{SMBCN}+\mathrm{SCND}
$$

Com essa divisão das figuras, as discussões passaram a ter como alvo as medidas dos segmentos: $\mathrm{AM}, \mathrm{MB}=\mathrm{CN}$ e $\mathrm{MD}$, sabendo que: $\mathrm{AB}=8 \mathrm{~m}, \mathrm{CD}=5 \mathrm{~m}$ e $\mathrm{MN}=\mathrm{BC}=16 \mathrm{~m}$, por serem segmentos paralelos, compreendidos por paralelas.

Uma das dificuldades percebidas durante a realização da atividade foi a construção da figura, principalmente para fechá-la a partir das medidas, por isso foram necessárias várias tentativas. A utilização do compasso foi um desafio e ressalta o quanto um ensino no modelo da racionalidade técnica deixa lacunas na formação do professor. Por fim, sob a mediação do professor pesquisador, foram construídas as figuras e partiu-se para o cálculo das áreas.

Com um transferidor, foram tomadas as medidas aproximadas dos ângulos, obtendo-se os seguintes valores: ângulo $\mathrm{DAB}=78^{\circ}$, ângulo $\mathrm{BCD}=127^{\circ} \mathrm{e}$ ângulo $\mathrm{CDA}=65^{\circ}$. Embora estejamos apenas descrevendo os resultados, muitas ações e trocas de ideias entre os participantes foram realizadas para utilização do transferidor na medida de ângulos e leitura em graus. Foi possível perceber a importância do trabalho em grupo para a superação das dificuldades com os instrumentos de medição e desenho. Dentre as ações realizadas durante essa prática, destacamos a busca de um transferidor na internet, uma vez que, a grande maioria não dispunha do instrumento no momento do curso. Os modelos de transferidor e orientação de como medir ângulos, além da leitura dessas medidas, possibilitaram a determinação dos ângulos da figura ABCD.

A partir da medida dos ângulos, tiveram início os procedimentos para o cálculo da área da superfície do triângulo retângulo AMD. A maioria dos grupos utilizou da expressão matemática usual para o cálculo da área de um triângulo: $\mathrm{S}=(\mathrm{a} \cdot \mathrm{b}) / 2 \mathrm{em}$ que a denota a base do triângulo e $\mathrm{b}$ a altura em relação a essa base.

Os elementos dados explicitamente na construção da figura foram: a medida do lado AD, o ângulo $\mathrm{a}=78^{\circ}$ e o ângulo $\mathrm{m}=90^{\circ}$. Para o cálculo da área do triângulo, os estudantes precisavam 
da medida dos segmentos MD e AM. Assim surgiu o questionamento: Como calcular a medida desses segmentos quando se conhecem os ângulos, adjacente ou oposto, a eles? Muitas discussões sobre a questão surgiram, mas chamou particularmente a atenção à falta de ideia sobre o assunto. Então, foi necessário fazer uma retomada das relações trigonométricas nos triângulos retângulos, que, para alguns poucos dos participantes, serviu como recordação e, para outros, como conhecimento novo, uma vez que atuavam em séries em que esse conteúdo não era utilizado.

Voltando à questão do triângulo AMD, do qual se conhece o ângulo reto e o maior dos lados $\mathrm{AD}$, denominado hipotenusa, precisavam conhecer a medida do segmento $\mathrm{MD}$ e de $\mathrm{AM}$, altura do triângulo.

Assim, sabendo que $\operatorname{sen} 78^{\circ}=0,978$

Então $0,978=$ ou $\quad=20,04 \cong 20 \mathrm{~m}$.

Para fins de cálculo, arredondamos o valor de MD para $20 \mathrm{~m}$.

O cálculo do segmento AM pode ser feito utilizando o teorema de Pitágoras

$\mathrm{AD} 2=\mathrm{AM} 2+\mathrm{MD} 2$, substituindo os valores temos:

$(20,5) 2=\mathrm{AM} 2+(20) 2$

$(\mathrm{AM}) 2=(20,5) 2-(20) 2$

$(\mathrm{AM}) 2=420,25-400$

$(\mathrm{AM})=$

$\mathrm{AM}=4,5 \mathrm{~m}$

Conhecidas a base e a altura, os grupos puderam utilizar a expressão para o cálculo da área da superfície do triângulo:

$\mathrm{SAMD}=$, substituindo os valores $\mathrm{MD}=20 \mathrm{~m}$ e $\mathrm{AM}=4,5 \mathrm{~m}$

$\mathrm{SAMD}==45 \mathrm{~m} 2$

Para o cálculo da área da superfície do retângulo $\mathrm{MBCN}$, conhecida a medida de $\mathrm{MB}=\mathrm{AB}$ $-\mathrm{AM}=8 \mathrm{~m}-4,5 \mathrm{~m}$, temos que $\mathrm{MB}=3,5 \mathrm{~m}$, e assim $\mathrm{BC}=16 \mathrm{~m}$, então:

$\mathrm{SMBCN}=\mathrm{MB} \times \mathrm{BC}, \mathrm{ou} \mathrm{SMBCN}=3,5 \mathrm{~m} \times 16 \mathrm{~m}=56 \mathrm{~m} 2$

Para o cálculo do triângulo NCD, temos que: $\mathrm{ND}=4,5 \mathrm{~m}$ e NC $=3,5 \mathrm{~m}$

$\mathrm{SNCD}==7,87 \mathrm{~m}^{2}$

Assim, somando as áreas encontraram:

$\mathrm{SABCD}=45 \mathrm{~m} 2+56 \mathrm{~m} 2+7,87 \mathrm{~m} 2=108,87 \mathrm{~m} 2$ (II)

A comparação entre os dois resultados dados por (I) e (II) ensejou um grande debate, pois alguns professores consideravam que, mesmo sendo uma diferença de aproximadamente $10 \mathrm{~m} 2$, em circunstâncias de não haver outros meios, o percentual de diferença gira em torno de $10 \%$, o que os componentes do grupo consideravam razoável. Já outros grupos consideravam que em 10 
m2 era possível colocar entre 100-150 frangos, conforme seguissem as recomendações para o número de frangos por $\mathrm{m} 2$ e que isso, para o caso em estudo, não era pouco, no sentido financeiro.

Essas discussões em âmbito escolar a partir das práticas com Modelagem Matemática constituem uma concepção de Modelagem na perspectiva da Educação Matemática que está preocupada com o ensino e a aprendizagem, mais do que com a aplicação da Matemática.

\section{Considerações finais}

Neste artigo, apresentamos uma revisão teórica que buscou apontar a racionalidade técnica como um fator possivelmente condicionante da prática pedagógica docente, impedindo a reflexão crítica devido à mecanização e à desapropriação da docência. Discutimos a inserção da racionalidade técnica na dimensão educativa brasileira e na história do Ensino de Ciências, defendendo que tal racionalidade vem burocratizando a mente e a prática docente, oprimindo e desumanizando professores e estudantes, trazendo perdas para os sujeitos na condição de cidadãos. Ao refletirmos sobre a contradição entre a qualidade ética e a qualidade técnica do ensino, baseadas em racionalidades opostas e constatando a hegemonia do modelo tecnicista sobre a formação e a prática docente, identificamos no referencial teórico analisado alguns elementos típicos dessa ideologia adaptativa.

As ações vivenciadas em um curso de formação a partir da concepção de Modelagem que se fundamenta, além da Matemática, nas Ciências Humanas e Sociais, podem mostrar uma nova perspectiva para a formação de professores, pois apresenta vários aspectos que se diferenciam do modelo tradicional. Na MM, todas as situações são contextualizadas e, nesse caso da construção rural, ficou evidente que os dados são coletados pelos próprios participantes que vivenciam as várias ações e procedimentos de coleta. Definir o tema a ser estudado acaba envolvendo gostos, necessidades, curiosidades e uma forma colaborativa de compartilhar o processo de ensino e de aprendizagem. Os procedimentos diferenciam-se por buscarem os dados sobre o tema das mais variadas maneiras, in loco sempre que possível, por decidir sobre o que pesquisar, onde buscar, trocar ideias, construir questões de interesse e defender seus pontos de vistas. Essa forma de proceder possibilita o desenvolvimento da capacidade de tomada de decisão, argumentação, a autonomia e a segurança decorrentes para ações futuras. O levantamento dos problemas pelos estudantes, ou pelos professores em formação, desenvolve a autonomia dos sujeitos, a capacidade de organizar dados e de reconhecer situações-problemas em diferentes contextos.

Destacamos que é importante resolver os problemas levantados, sejam eles matemáticos ou de outras naturezas como sociais, econômicas, ambientais, administrativas, ecológicas entre outras. Outro diferencial do trabalho com MM é a possibilidade de uma perspectiva interdisciplinar, multidimensional ou mesmo transdisciplinar, pois, além dos conteúdos matemáticos, conhecimentos de outras naturezas são mobilizados para a resolução das questões, enfatizando a importância das diferentes áreas do conhecimento para formação inicial ou continuada do professor da Educação Básica.

A etapa da análise crítica é outro diferencial em relação ao modelo da racionalidade técnica, pois promove a reflexão sobre o que foi realizado, com um olhar direcionado pelas discussões que se constitui em metacognição, que, em última instância, promove o monitoramento das próprias ações pelos envolvidos. No caso aqui apresentado, a discussão dos resultados enfatizou as diferenças entre as metragens encontradas pelo "método prático" e pela decomposição da figura irregular em triângulos e retângulos. Assim, foram discutidas duas maneiras para resolver o problema da área e as implicações matemáticas sobre a utilização correta das fórmulas, além do pensamento matemático envolvido e o fator econômico, pois o erro no cálculo da área do barracão

Práxis Educativa, Ponta Grossa, v. 15, e2014239, p. 1-20, 2020

Disponível em: < https://www.revistas2.uepg.br/index.php/praxiseducativa> 
pode ensejar prejuízos financeiros, considerando a quantidade de frangos indicada por metro quadrado.

Os professores em formação vivenciaram todas as etapas previstas para o desenvolvimento de uma prática com Modelagem na perspectiva da Educação Matemática, revelando uma formação a qual oportuniza interações e diálogos, algo que o modelo da racionalidade técnica não propicia. A compreensão e as assimilações dessas etapas, mesmo não rígidas, promovem ações e interações que diferenciam a dinâmica de participação dos envolvidos. A vivência das etapas é importante, pois as ações e as interações que são favorecidas nos intercâmbios entre os participantes contribuem para a melhor compreensão da metodologia, ao mesmo tempo que fornece uma possibilidade diferente para a formação inicial e continuada de professores de Matemática para a Educação Básica.

De acordo com Macenham, Tozetto e Brandt (2016, p. 508), “[...] a reflexão crítica pautada no conhecimento científico possibilita a emancipação do professor perante as atividades desenvolvidas e a mecanização cede espaço para a razão, a consciência das condições da docência e a capacidade de transformações", por isso tamanha a contribuição desse tipo de atividade para a formação docente. Destacamos que nessa metodologia o sujeito participante (estudante ou no caso, professor em formação) é protagonista ao longo de toda a prática, desde a escolha do tema até a análise crítica das soluções. O participante é agente ativo, responsável pela sua aprendizagem tanto da solução matemática, do conteúdo envolvido, como da sua coerência, das estratégias de pensamento utilizadas e também do ponto de vista social, econômico, histórico, cultural e antropológico que possa emergir em cada situação.

Os temas a serem estudados partem do interesse dos participantes, pois são, muitas vezes, situações enfrentadas no dia a dia, e esse é um fator importante para promover motivação e gosto pela atividade na busca dos dados, nas problematizações, na compreensão do conteúdo matemático necessário para resolver a questão, que ganha mais sentido e significado por conta do contexto. Assim, um fator que favorece um novo modelo de formação e de racionalidade é dado pelos quefazeres da própria metodologia. Os encaminhamentos da atividade exigem nova postura de professores e estudantes, além de uma nova maneira de compreender o ensino e a aprendizagem, tendo como foco principal a formação humana.

Ao utilizar a Modelagem como uma metodologia para o ensino da Matemática, especificamente na Educação Básica, o professor tem a função de mediação, orientação, colocando aspectos para encaminhar as tomadas de decisões dos participantes em relação às questões matemáticas e não matemáticas. Portanto, podemos prever expectativas promissoras no trabalho com Modelagem Matemática na perspectiva da Educação Matemática, tal como assumida nesse trabalho, fundamentada e embasada em referenciais teóricos consistentes e coerentes com o tipo de ser que desejamos formar. Acreditamos que as práticas com MM possam se constituir em um novo modelo de formação para o professor, promovendo em âmbito escolar uma nova maneira de propiciar ensino e aprendizagem de Matemática, que promova aspectos importantes e tão necessários às aprendizagens de um cidadão do século XXI.

\section{Referências}

BALDINO, R. R. Ensino de Matemática ou Educação Matemática? Revista Temas e Debates, Lisboa, v. 4, n. 3, p. 51-60, 1991. 
BRANDT, C. F.; TOZETTO, S. S. Reflexões sobre letramento crítico para a docência em Matemática em cursos de formação de professores. Práxis Educativa, Ponta Grossa, v. 4, n. 1, p. 73-83, jan./jun. 2009. DOI: https://doi.org/10.5212/PraxEduc.v.4i1.073083

BURAK, D. Modelagem Matemática: ações e interações no processo de ensino-aprendizagem. 1992. 460 f. Tese (Doutorado em Educação) - Universidade Estadual de Campinas, Campinas, 1992.

BURAK, D. A modelagem matemática e a sala de aula. In: ENCONTRO PARANAENSE DE MODELAGEM EM EDUCAÇÃO MATEMÁTICA - EPMEM, 1., 2004, Londrina. Anais [...]. Londrina: Departamento de Matemática, 2004. p. 1-10.

BURAK, D. Modelagem na Perspectiva da educação matemática: um olhar sobre seus fundamentos. Revista Iberoamericana de Educación Matemática, v. 13, n. 51, p. 9-26, dez. 2017. DOI: https://doi.org/10.36661/2596-318x.2019v1i1.10740.

BURAK, D.; KLÜBER, T. E. Educação Matemática: contribuições para a compreensão de sua natureza. Acta Scientiae, Canoas, v. 10, p. 93-106, jul./dez. 2008.

CALDEIRA, A. D. Modelagem Matemática: um outro olhar. Alexandria - Revista de Educação em Ciência e Tecnologia, Florianópolis, v. 2, n. 2, p. 33-54, jul. 2009.

CARR, W.; KEMMIS, S. Becoming critical: education, knowledge and action research. London and Philadelphia: The Palmer Press, 1986.

D’AMBROSIO, U. Algumas notas históricas sobre a emergência e a organização da pesquisa em educação matemática, nos Estados Unidos e no Brasil. In: MIGUEL, A. et al. A educação matemática: breve histórico, ações implementadas e questões sobre sua disciplinarização. Revista Brasileira de Educação, Rio de Janeiro, n. 27, p. 71-73, 2004.

D`AMBROSIO, U. Pesquisa qualitativa em educação Matemática. In: BORBA, M. de C.; ARAUjO, J. L. (Orgs.). Pesquisa Qualitativa em Educação Matemática. Belo Horizonte: Autêntica, 2006. p. 9-21. (Coleção Tendências em Educação Matemática).

DUARTE, A. R. S.; SILVA, M. C. L. Abaixo Euclides e acima quem? Uma análise do ensino de Geometria nas teses e dissertações sobre o Movimento da Matemática Moderna no Brasil. Práxis Educativa, Ponta Grossa, v. 1, n. 1, p. 87-93, jan./jun. 2006.

DUARTE, M. S. et al. Perspectivas para além da racionalidade técnica na formação de professores das ciências. In: ENCONTRO NACIONAL DE PESQUISA EM EDUCAÇÃ̃O E CIÊNCIAS, 7. 2009, Florianópolis. Anais eletrônicos [...]. Florianópolis: UFSC, 2009. Disponível em: <http://posgrad.fae.ufmg.br/posgrad/viienpec/pdfs/novo_07.pdf>. Acesso em: 10 fev. 2020.

FIORENTINI, D. Alguns modos de ver e conceber o ensino da matemática no Brasil. Revista Zetetiké, Campinas, v. 3, n. 4, p. 1-37, 1995.

HIGGINSON, W. On the foundations of mathematics education. For the learning of Mathematics, v. 1, n. 2, p. 3-7, 1980. 
KLÜBER, T. E. BURAK, D. Sobre os objetivos, objetos e problemas da pesquisa brasileira em Modelagem Matemática na Educação Matemática. Práxis Educativa, Ponta Grossa, v. 7, n. 2, p. 467-488, jul./dez. 2012. DOI: https://doi.org/10.5212/PraxEduc.v.7i2.0008

MACENHAM, C.; TOZETTO, S. S.; BRANDT, C. F. Formação de professores e prática pedagógica: uma análise sobre a natureza dos saberes docentes. Práxis Educativa, Ponta Grossa, v. 11, n. 2, p. 505-525, maio/ago. 2016. DOI: https://doi.org/10.5212/PraxEduc.v.11i2.0011

MORIN, E. Da necessidade de um pensamento complexo. In: MARTINS, F. M.; SILVA, J. M. da S. (Orgs.). Para navegar no século XXI: tecnologias do imaginário e cibercultura. Porto Alegre: Sulina, Edipucrs, 2000. p. 19-42.

MORIN, E. A cabeça bem-feita: repensar a reforma, reformar o pensamento. Tradução Eloá Jacobina. 8. ed. Rio de Janeiro: Bertrand Brasil, 2003.

PETRAGLIA, I. C. Edgar Morin: a educação e a complexidade do ser e do saber. 9. ed. Petrópolis: Vozes, 2005.

PIMENTA, S. G. Professor reflexivo: Construindo uma crítica. In: PIMENTA, S.; GUEDIN, E. Professor reflexivo no Brasil: gênese e crítica de um conceito. São Paulo: Cortez, 2002. p. 17-52.

RIUS, E. B. Educación Matemática: una reflexión sobre su naturaleza y sobre su metodologia. Educación Matemática, México, v. 1, n. 2, p. 28-42, 1989.

ROCHA, T. L. Da racionalidade técnica ao professor reflexivo. Cadernos da Fucamp, Monte Carmelo, v. 13, n. 18, p. 119-127, 2014.

SANTOS, B. de S. Um discurso sobre as ciências na transição para uma ciência pós-moderna. Estudos Avançados, São Paulo, v. 2, n. 2, p. 46-71, 1988.

SCHÖN, D. The reflective practitioner. New York: Basic Books, 1983.

Recebido em 22/08/2019

Versão corrigida recebida em 22/01/2020

Aceito em 24/01/2020

Publicado online em 17/02/2020 